\title{
Notification List Notification that new names and new combinations
have appeared in volume 60 , part 2 , of the IJSEM
}

Correspondence

Jean Euzéby

email address can be found at www.bacterio.net
This listing of names published in a previous issue of the IJSEM is provided as a service to bacteriology to assist in the recognition of new names and new combinations. This procedure was proposed by the Judicial Commission [Minute 11(ii), Int J Syst Bacteriol 41 (1991), p. 185]. The names given herein are listed according to the Rules of priority (i.e. page number and order of valid publication of names in the original articles). Taxonomic opinions included in this List (i.e. the creation of synonyms or the emendation of circumscriptions) cannot be considered as validly published nor, in any other way, approved by the International Committee on Systematics of Prokaryotes and its Judicial Commission.

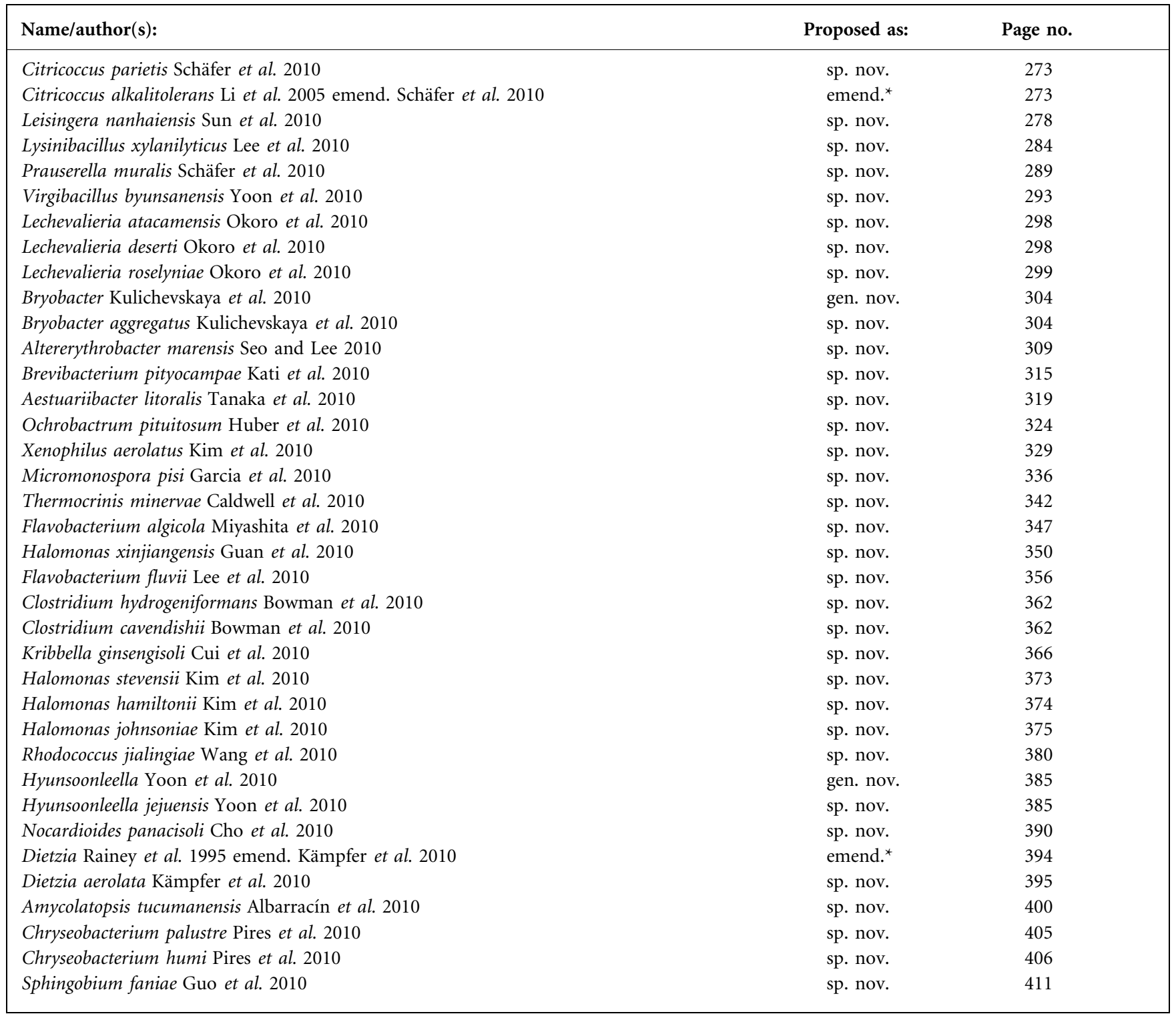


cont.

\section{Name/author(s):}

Sphingobium scionense Liang and Lloyd-Jones 2010

Flavobacterium caeni Liu et al. 2010

Fontibacillus Saha et al. 2010

Fontibacillus aquaticus Saha et al. 2010

Sphingobium quisquiliarum Bala et al. 2010

Alkalibacillus flavidus Yoon et al. 2010

Mycobacterium paraseoulense Lee et al. 2010

Thiohalobacter Sorokin et al. 2010

Thiohalobacter thiocyanaticus Sorokin et al. 2010

Dietzia timorensis Yamamura et al. 2010

Methanobacterium veterum Krivushin et al. 2010
Proposed as:

Page no.

sp. nov.

sp. nov.

gen. nov.

sp. nov.

sp. nov.

sp. nov.

sp. nov.

gen. nov.

sp. nov.

sp. nov.

sp. nov.
415

420

426

426

432

437

442

447

447

452

457

*Taxonomic opinion. 